\title{
Valorisation par des vaches laitières de deux variétés de maïs de digestibilité différente
}

\author{
P Brunschwig 1, P Augeard 2, B Carpentier 3
}

\begin{abstract}
1/nstitut de l'Elevage, 14 avenue Joxé, BP 646, 49006 Angers Cedex 01 ; 2 Chambre d'Agriculture de Maine-et-Loire, EDE, La Quantinière, 49800 Trélazé ; ${ }^{3}$ Association Générale de Producteurs de Maïs, Rue Frère Gagne, BP 463, 60021 Beauvais Cedex, France
\end{abstract}

La prévision de la valeur énergétique du maïs ensilage nécessite de déterminer le coefficient d'utilisation digestive de la matière organique in vivo sur moutons "standard". En laboratoire, pour les mesures de routine, cette estimation passe par le dosage de constituants chimiques, la mesure de la solubilité enzymatique in vitro (Aufrère et Michalet-Doreau, 1988, Anim Feed Sci Technol, 20, 203-218) ou la spectroscopie dans le proche infra rouge. Des animaux à fort niveau de production montrent-ils des performances zootechniques différentes sur des maïs dont la digestibilité ainsi prédite est différente? Un programme d'essais sur taurillons et vaches laitières est réalisé dans ce sens avec la collaboration de SEPROMA (Syndicat des producteurs de semences de maïs) ; on relate ici le premier essai sur vaches laitières réalisé à la ferme des Trinottières.

L'essai a été réalisé sur 2 lots de 15 vaches Prim'Holstein en phase descendante de lactation durant 16 semaines selon un schéma en blocs complets équilibrés. Les deux variétés de maïs utilisées ont été cultivées sur les mêmes parcelles et selon le même itinéraire technique ; elles appartenaient au même groupe de précocité. La teneur en MS du maïs $X$ était supérieure de 4,5 points à celle de $A$ $(31,1 \%)$. La teneur en $C B$ n'a pas été différente entre $A$ et $X$ (208 versus $222 \mathrm{~g} / \mathrm{kg}$ MS) ; de même pour l'amidon (246 versus 267 $\mathrm{g} / \mathrm{kg}$ MS). La teneur en MAT du maïs $X$ était plus faible de $12,2 \mathrm{~g}$ que celle du maïs $\mathrm{A}(80,7$ $\mathrm{g} / \mathrm{kg} M S$ ). Le maïs $A$ a montré une solubilité enzymatique (méthode Aufrère) de 66,3\% supérieure de 3,2 points à celle du maîs $X$. La digestibilité mesurée sur mouton standard du maïs $X$ a été inférieure de 2,7 points à celle $d u$ maïs $A(68,6 \%)$.

Les vaches des lots $A$ et $X$ ont reçu en ration complète mélangée le maïs expérimental $A$ ou $X$ avec une même proportion d'aliments concentrés $(20 \%)$. Le concentré comportait $37 \%$ de tourteaux tannés et $63 \%$ de tourteau de soja.

La consommation totale de MS n'a pas été modifiée par la plus faible digestibilité du maïs $X$. Les apports énergétiques totaux, calculés à partir de la digestibilité des maīs mesurée sur moutons, ont été de 15,9 UFL/j (A) et $14,7 \mathrm{UFL} / \mathrm{j}(\mathrm{X})$. La production laitière a été significativement plus faible pour le lot $X$ $(-3,7 \mathrm{~kg})$. Les quantités de matières grasses et protéiques du lot $X$ ont été significativement plus faibles que celles du lot $\mathrm{A}$ (de respectivement - 97 et - $126 \mathrm{~g} / \mathrm{j}$ ). L'augmentation de TB dans le lot X (+ 2,4 g/kg) traduit une concentration du lait en matières grasses ; parallèlement, le TP a tendance à baisser. La valorisation énergétique du maïs $X$ par les animaux est inférieure de $5,5 \%$ à celle du maïs A $(0,96$ UFL $\mathrm{kg} M S)$.

Lorsque les apports azotés ne sont pas limitants, la consommation d'un maïs prédit à digestibilité de la matière organique inférieure s'est traduit par une baisse des performances laitières des vaches. Ces résultats méritent d'être confirmés.

$\begin{array}{lccc}\text { régime } & \mathrm{A} & - & \mathrm{X} \\ \text { MS totale ingérée }(\mathrm{kg}) & 17,7^{\mathrm{a}} & & 17,0^{\mathrm{a}} \\ \text { Lait brut }(\mathrm{kg} / \mathrm{j}) & 25,4^{\mathrm{a}} & & 21,7^{\mathrm{b}} \\ \mathrm{TB}(\mathrm{g} / \mathrm{kg}) & 40,4^{\mathrm{a}} & & 42,8^{\mathrm{b}} \\ \mathrm{TP}(\mathrm{g} / \mathrm{kg}) & 31,1^{\mathrm{a}} & & 30,6^{\mathrm{a}} \\ \text { Gain de poids quotidien }(\mathrm{g} / \mathrm{j}) & 147^{\mathrm{a}} & 116^{\mathrm{a}} \\ \mathrm{a}, \mathrm{b}: \text { différences significatives au seuil } 5 \% & & \end{array}$

